\title{
Social Identification Dimensions as Mediators of the Effect of Prototypicality on Intergroup Behaviours
}

\author{
Patricia L. Obst ${ }^{1}$, Katherine M. White ${ }^{1}$, Kenneth I. Mavor ${ }^{2}$, Rosland M. Baker ${ }^{1}$ \\ ${ }^{1}$ School of Psychology and Counseling, Queensland University of Technology, Brisbane, Australia; \\ ${ }^{2}$ School of Health and Psychological Sciences, Australian National University, Canberra, Australia. \\ Email: p.obst@qut.edu.au \\ Received May $5^{\text {th }}$, 2011; revised June $6^{\text {th }}$, 2011; accepted July $18^{\text {th }}, 2011$.
}

\begin{abstract}
Cameron (2004) proposed a three-dimensional model and measure of social identification consisting of cognitive centrality, in-group affect, and in-group ties. This approach has received growing theoretical and empirical support; however, little research has examined how these dimensions of social identification may relate differentially to intergroup outcome behaviors. The current research sought to address this question by examining the possible mediating role the dimensions of social identification on the relationship between prototypicality of group members and the intergroup outcome behaviors of in-group favoritism, out-group derogation, and collective self-esteem. The current study examined university students' $(\mathrm{N}=235)$ feelings towards students from their own and another local university. Structural equation modeling was used to identify the most appropriate and parsimonious models of these pathways. The results showed support for the utility of measuring social identification using a multidimensional approach with unique meditational pathways emerging for the distinct intergroup behaviors.
\end{abstract}

Keywords: Social Identification, Prototypicality, Intergroup Outcomes

\section{Introduction}

The construct of social identity has become one of increasing importance in the social psychology literature since the development of Social Identity Theory (SIT) (Tajfel, 1978; Tajfel \& Turner, 1979). An improved understanding of this construct is due to the development of valid indicators, many of which are derived from the scale developed by Brown et al. (1986). While early work tended to view and measure social identity as a unidimensional concept, treating identification as a general attachment to an in-group, there is growing evidence within the field to suggest that this approach is inadequate (see Ashmore, Deaux, \& McLaughlin-Volpe, 2004). Indeed, Tajfel's (1978) original definition of the construct of social identity, referring to an individual's knowledge of belonging to a social group, together with the emotional and value significance of that group membership, reflects multidimensionality. Knowledge of belonging to a particular group points towards a cognitive awareness, while the emotional significance indicates an affective dimension, and the value significance points towards an evaluative aspect.

Deaux (1996) argues that cognitive processes, emotional associations, and interdependence between group members are all important aspects of social identity. Karasawa (1991) distinguished between identity with the group and identity with group members. Smith, Murphy, and Coats (1999) argue that group attachment is distinct from other forms of group identifycation. Ashmore et al. (2004) proposed an organizational framework of collective identity incorporating work from several theoretical perspectives-Social Identity Theory (Tajfel \& 1978, Self Categorization Theory (Turner et al., 1987), and Identity Theory (Stryker, 1987.) This framework suggests that collective identity is multifaceted and includes seven broad dimensions: self-categorization, evaluation, importance, attachment and interdependence, social embeddedness, behaveioral involvement, and content and meaning. Each dimension then has several elements that, in turn, underlie the dimension. This framework suggests further that the varied aspects of identification may be related differentially to a number of intergroup outcomes.

Within social identity literature, a number of researchers have found empirical evidence for a multidimensional concepttualization of social identity (e.g., Cameron \& Lalonde, 2001; Ellemers, Kortekaas \& Ouwerkerk, 1999; Hinkle et al., 1989; Jackson, 2002). Hinkle et al. (1989) found evidence for a multidimensional view of social identity composed of an affective aspect, a cognitive aspect, and a group dynamics aspect. Ellemers et al. (1999) reported findings supportive of three factors of social identity: group self-esteem, self-categorization, and commitment to the group. Jackson (2002) also presented evidence that supported three factors underlying the construct of social identity: self-categorization, evaluation of the group, and perceptions of solidarity. While the factor structure of social identity does vary across these studies, the concept of the multidimensionality of social identity has received strong empirical support.

Recently, Leach et al. (2008) have presented a hierarchical model of in-group identity which conceptualise subcomponents that fit within two broad dimensions. Leach et al. distinguish between group-level self-definition (i.e., individual self-stereotyping, in-group self-stereotyping) and self-investment (solidarity, positive evaluation, and centrality). These authors suggest that individuals may identify in different ways with distinct groups. For example, the authors distinguish between the way artificially created groups and real world groups identify with their in-group. They suggest that, as artificially created groups 
have little prior history or interaction or shared members, in-group identification is likely to be based in group-level selfdefinition. Real world groups, on the other hand, with longer histories and interaction, would be more likely to identify in terms of self investment such as positive evaluation, solidarity, and centrality.

Cameron (2004) developed a model and valid measure of social identity based on studies of in-group identification of real world groups that capture the elements of Leach et al.'s (2008) self investment category of social identification. Cameron's model describes social identity as having the three dimensions: cognitive centrality, in-group affect, and in-group ties. Cognitive Centrality is the amount of time spent thinking about being a group member or the cognitive salience of a given group membership, which is similar to the self categorization dimensions which emerged in Ellemers et al.'s (1999) and Jackson's (2002) findings and the centrality dimension of Leach and colleagues. In-group Affect, the positivity of feelings associated with membership in the group, encapsulates the affective dimension that has emerged in many studies (e.g., Ellemers et al., 1999; Hinkle et al., 1989; Jackson, 2002) and is similar to the positive evaluation component proposed by Leach and colleagues. In-group Ties is the perception of similarity and bonds with other group members and is also in line with much previous research (e.g., Ellemers et al., 1999; Hinkle et al., 1989; Jackson, 2002; Karasawa, 1991) and comparable to the solidarity component proposed by Leach and colleagues.

Over the course of several studies, Cameron (2004) developed a 12-item scale measuring these three factors. Evidence for Cameron's conceptualization of social identity has been found across several studies examining social identity with geographical and internet communities (Obst, Smith, \& Zinkiewicz, 2002; Obst, Zinkiewicz \& Smith, 2002), and gen- der and race (Boatswain \& Lalonde, 2000; Cameron \& Lalonde, 2001). Cameron (2004) tested a unidimensional model of social identity, a two dimensional model (cognitive and emotional aspects), and a three-factor model (cognitive centrality, in-group ties, and in-group affect) and found that the data were best explained by the three-factor model.

In an additional test of a three-dimensional model of social identity, Obst and White (2005) assessed participants' social identity across three distinct group memberships. Confirmatory factor analysis of these data supported the three-factor model of social identity in comparison to fit indices for one- and two-factor models. In addition, this study found that different patterns of means and correlations emerged across groups on the three dimensions, supporting the utility of this multidimensional model of social identity.

More recent investigations of the Cameron (2004) model have found support for the model in various contexts, including community (Bilewicz \& Wójcik, 2010; Harris, Cameron \& Lang, 2011), organization (Harris \& Cameron, 2005), and collective action (Giguére \& Lalonde, 2010). However, while these studies have focused on identification within intragroup contexts, the present investigation focused on examining the influence of the distinct dimensions of social identification in an intergroup context. The Leach et al. (2008) studies presented some strong evidence for the discriminant validity of the dimensions of social identification. The present study will provide a useful addition to such research, as well as providing an insight into potential underlying processes by focusing on distinct in-tergroup processes (e.g., collective self-esteem, in-group favouritism, and out-group derogation).

\section{Collective Self-Esteem}

Consistent with several theoretical perspectives on the self-concept (e.g., Maslow, 1968), SIT posits that individuals are motivated to achieve and maintain a high level of self-esteem. However, whereas other perspectives focus on maintaining a positive personal identity (i.e., personal self-esteem), SIT is primarily concerned with the motivation to maintain a positive social identity (i.e., collective self-esteem; Crocker \& Luhtanen, 1990). While personal self-esteem is characterized by self-perceptions of attractiveness and likeability, collective self-esteem is characterized by the positive or negative beliefs that group members hold in relation to their social identity (Hogg \& Williams, 2000; Tajfel, 1978) and, hence, is likely to be associated closely with in-group affect. Cameron's (1999, 2004) studies indicated that collective self-esteem was positively and moderately correlated with in-group affect and in-group ties, but not with cognitive centrality.

\section{Intergroup Bias}

In order to achieve and maintain positive collective self-esteem, SIT predicts that group members will engage in intergroup bias behaviors as a means of positively differentiating the in-group from the out-group (Schmitt \& Branscombe, 2001). These behaviors often take the forms of in-group favoritism and out-group derogation (Brown, 2000; Lindeman, 1997). The effect of intergroup bias has been demonstrated consistently in empirical research even in circumstances where there are few or no obvious extrinsic causes. For example, some evidence comes from studies using the minimal group paradigm in which individuals are divided into groups on the basis of trivial or arbitrary distinctions (Tajfel, Billig, Bundy \& Flament, 1971), explicitly excluded from evaluations, and do not benefit from the rewards. In these studies, participants still allocate more rewards to members of the in-group than to the out-group (e.g., Brewer, 1979; Diehl, 1990; Corenblum \& Stephen, 2001; Jetten, Spears \& Manstead, 1997), evaluate out-group members less favourably than in-group members (e.g., Schmitt \& Branscombe), and regard products of the in-group to be superior to those of the out-group (Ashforth \& Mael, 1989; Wann \& Grieve, 2005). Leach et al. (2008) argue that, as centrality encapsulates notions of salience and importance, the relationship between centrality and inter-group-outcomes is likely to be stronger. Several studies have also shown that higher cognitive centrality is associated with stronger intergroup discrimination (Cameron, 1999, 2004; Cameron \& Lalonde, 2001).

\section{Prototypicality}

Further to these findings in minimal group paradigms, studies have shown that intergroup bias behaviors are strongest among prototypical group members (e.g., Branscombe \& Wann, 1994; Vivian, Brown \& Hewstone, 1995; Verkuyten \& Nekuee, 1999). Comparisons between the in-group and out-group lead to the representation of groups in terms of prototypes (Jetten et al., 1997). These prototypes refer to a contextually-appropriate set of descriptive and prescriptive cognitive representations of group-specific ways to think, feel, and behave which, in turn, 
allows for group members to evaluate themselves according to the same standards used to evaluate other group members (Hogg, Abrams, Otten, \& Hinkle, 2004). Prototypical group members are defined as being similar to the in-group prototype and dissimilar from the out-group prototype (Hogg et al., 2004). Researchers have shown consistently that prototypical group members are typically evaluated more positively by themselves and other in-group members (Castano, Paladino, Coull, \& Yz- erbyt, 2002); are higher in collective self-esteem (Jetten et al., 1997); and are more likely to engage in out group derogation as a way of increasing collective self-esteem (Branscombe \& Wann, 1994).

\section{The Current Study}

Several studies support the notion of different relationships between dimensions of social identification and intergroup outcomes (e.g. Ellemers et al., 1999, Leach et al., 2008), however, there is still a limited understanding of which specific aspects of identification predict which specific collective perceptions and behaviors. The current study aims to expand on previous research by examining in greater detail the influence of the proposed dimensions of social identity or what Leach and colleagues (2008) would classify as self investment identity dimensions on intergroup outcomes behaviors of in-group favoritism, out-group derogation, and collective self-esteem. Data were collected via a cross-sectional study of psychology students from a large Australian university; the study assessed students' attitudes towards both students from their own and another local university. Based on previous research (e.g., Jetten et al., 1997), it was hypothesized that students' perceived prototypicality as a student of their specific university would be related positively to their social identification and levels of in-group favoritism, out group derogation, and collective selfesteem. It was hypothesized further that the effect of prototypicality on in-group favoritism, out-group derogation, and collective self-esteem would be differentially mediated by the dimensions of social identification (centrality, in-group affect and ingroup ties). Cameron (2004) and Cameron and Lalonde (2001) indicated that the cognitive dimension of social identifycation is linked with stronger intergroup discrimination and in-group affect with collective self-esteem. It was hypothesized that ingroup affect would be the strongest mediator of the prototypicality and collective self-esteem relationship, and centrality would be the strongest mediator of the relationship between prototypicality and both in-group favoritism and out-group derogation.

\section{Method}

\section{Participants}

Two hundred and thirty-five undergraduate Queensland University of Technology students (48 males and 187 females) participated in the study for course credit. The mean age of participants was 23.48 years ( $\mathrm{SD}=7.65)$, with a range of 17 to 52 years.

\section{Procedures and Measures}

The design and several measures were based on Jetten and colleagues (put in reference here to be correct re APA1997). Students were approached in class and invited to participate in a study about how their beliefs in supernatural phenomena compared with those of students from another local university (of approximately comparable status). Piloting of the survey indi- cated that the topic of supernatural phenomenon was not linked to the status of the groups or seen as of central importance to students. The survey contained a small questionnaire of beliefs in supernatural phenomenon and the following measures.

In-group favouritism. Participants were told that the experimenters were interested to know how they, as students, felt about the allocation of resources for universities. Participants were asked to distribute - as they saw fit-a number of grants, scholarships, and delegations to a university student conference between (their in-group) QUT students and (an out-group) Griffith University students. The combined percentages of these allocations to QUT students formed the indicator of in-group favoritism out of a possible $100 \%$ allocation of all resources to QUT students. This measure was internally reliable ( $\alpha=$.87).

Out-group derogation. Participants were then asked to complete a 12-item questionnaire regarding their feelings towards (out-group) Griffith University students, which consisted of adapted items such as 'I admire Griffith students' and 'I feel superior to Griffith students’. This measure was designed by Stephen and Stephen (1993), and has been used in previous studies to reflect any negative affect relating to out-groups (e.g., Corenblum \& Stephen, 2001). The scale includes the following evaluative and emotional terms: hostility, admiration, disliking, acceptance, superiority, affection, disdain, approval, hatred, sympathy, rejection, and warmth. All items were responded to on a Likert scale ranging from 1 (strongly disagree) to 7 (strongly agree) and the 12 item scores were added to give a total score with higher scores indicating greater out-group derogation. This measure was reliable $(\alpha=.81)$.

Collective self-esteem. Collective self-esteem in relation to one's in-group was measured using three items: 'At the moment I am pleased to be a student at QUT'; 'At the moment I have a good feeling about being a student at QUT'; and 'At the moment I am satisfied about the fact that I am a student at QUT’ (Doosje, Ellemers, \& Spears, 1995; Jetten et al., 1997). Responses were indicated on a Likert scale ranging from 1 (strongly disagree) to 7 (strongly agree). Scores on the three items were summed to give an aggregate collective self-esteem score. This measure was reliable $(\alpha=.95)$.

Social identification. Participants were asked to complete the 12 items from Cameron's (2004) “Three Dimensional Strength of Group Identification Scale”. Four items assessed each aspect of the three-dimensional model of social identification in relation to one's in-group: cognitive centrality (e.g., 'I often think about being a QUT student'; $\alpha=.80$ ); in-group affect (e.g., 'In general I'm glad to be a QUT student'; $\alpha=.80$ ); and in-group ties (e.g., 'I feel strong ties to other QUT students'; $\alpha=.83$ ). Responses were indicated on a Likert scale ranging from 1 (strongly disagree) to 7 (strongly agree).

Prototypicality. Based on the item used by Jetten et al. (1997) to assess self-perceptions of in-group prototypicality, participants were asked to respond to the statement: 'Overall, I perceive myself as being a typical QUT student' on a Likert scale ranging from 1 (strongly agree) to 7 (strongly disagree).

\section{Results}

\section{Preliminary Analyses}

Preliminary analyses revealed no significant missing data or 
breaches of normality. Total scales were calculated based on responses for a minimum of $75 \%$ of completed items per scale. The correlations between prototypicality, the dimensions of social identification, and the intergroup outcome behaviors are shown in Table 1.

\section{Main Analyses}

The meditational models were tested via AMOS. For each outcome variable of in-group favoritism, out-group derogation, and collective self-esteem, the initial model included prototypicality and the potential mediators: cognitive centrality, in-group affect, and in-group ties. The model included correlated error-terms for the social identity scales to capture the common variance not associated with prototypicality. High correlations between the three social identity subscales could potentially cause some instability in models containing all three mediators; however, in this case, the zero-order correlations among the social identity scales are small to moderate (see Table 1) and, thus, potentially can act as somewhat independent mediators. The final models presented are those that produced the most parsimonious and best fitting models after removing non-significant pathways. The pathways weightings presented in the models are standardized for comparability. Figures 1(a) 2(a), and 3(a) show the initial pathways for each outcome variable, and Figures 1(b), 2(b), and 3(b) show the final best fit ting model for each outcome variable. Table 2 presents model fit for the initial and final models for each outcome variable.

\section{Discussion}

The aim of the current study was to investigate whether the dimensions underlying social identification would differentially mediate the relationship between prototypicality and the intergroup outcome behaviours of in-group favoritism, out-group derogation, and collective self-esteem. As demonstrated in previous studies, the results of the current study supported the hypothesis that prototypicality was positively related to the dimensions of social identification and to the outcome behaveiours of in-group favoritism, out-group derogation, and collective self-esteem. Furthermore, the results supported the hypothesis that the dimensions underlying social identification differentially mediate the relationship between prototypicality and these intergroup outcome behaviours.

Specifically, highly prototypical students who reported high levels of centrality engaged in more in-group favoritism and out-group derogations. This finding is consistent with previous research in this area in which a cognitive dimension has been shown to repeatedly appear in measures of social identification (e.g., Cameron, 2004; Cameron \& Lalonde, 2001; Jackson, 2002) and has been linked with stronger intergroup discrimination (Cameron, 1999, 2004; Cameron \& Lalonde, 2001).

Further, an interesting finding emerged in terms of out-group derogation. Consistent with previous research, the regression pathways revealed that the cognitive dimension of centrality was positively related to out-group derogation indicating, as expected,

Table 1.

Correlations ( $r$ ) between prototypicality, the dimensions of social identification, and the intergroup outcome behaviours.

\begin{tabular}{|c|c|c|c|c|c|c|c|c|}
\hline & $\alpha$ & $\mathrm{M}(\mathrm{SD})$ & 1 & 2 & 3 & 4 & 5 & 6 \\
\hline Prototypicality & & $3.91(1.25)$ & 1 & & & & & \\
\hline Centrality & .80 & $4.12(1.32)$ & $.15^{*}$ & 1 & & & & \\
\hline In-group Affect & .80 & $3.27(.98)$ & $.25^{* *}$ & $.40 * *$ & 1 & & & \\
\hline In-group Ties & .83 & $3.52(1.21)$ & $.39 * *$ & $.18^{* *}$ & $.37^{* *}$ & 1 & & \\
\hline In-group Favouritism & .87 & $58.42(16.39)$ & $.14^{*}$ & $.19 * *$ & .05 & .07 & 1 & \\
\hline Out-group Derogation & .81 & $3.03(.832)$ & .02 & $.17^{* *}$ & $-.19 * *$ & .06 & $.24 * *$ & 1 \\
\hline Collective Self Esteem & .95 & 5.09 (1.03) & $.28^{* *}$ & $.36^{* *}$ & $.76^{* * *}$ & $.41^{* *}$ & .05 & .10 \\
\hline
\end{tabular}

Note. ${ }^{*} \mathrm{p}<.05, * * \mathrm{p}<.01, * * * \mathrm{p}<.01$; scales are $1-7$, IF is a percentage.

Table 2.

Model Fit statistics for the initial and final model for collective self-esteem, in-group favouritism and out-group derogation.

\begin{tabular}{|c|c|c|c|c|}
\hline Model & $\chi^{2}$ & CFI & RMSEA & AIC \\
\hline \multicolumn{5}{|c|}{ Collective Self-Esteem } \\
\hline Initial Model & $\chi^{2}(1)=2.2$ & .995 & .080 & 30.24 \\
\hline Final Model & $\chi^{2}(1)=2.4$ & .996 & .073 & 20.47 \\
\hline \multicolumn{5}{|c|}{ In-group Favoritism } \\
\hline Initial Model & $X^{2}(1)=02$ & .999 & .098 & 40.00 \\
\hline Final Model & $X^{2}(1)=.23$ & .999 & .010 & 16.23 \\
\hline \multicolumn{5}{|c|}{ Out-group Derogation } \\
\hline Initial Model & $X^{2}(1)=47$ & .997 & .091 & 38.47 \\
\hline Final Model & $X^{2}(1)=2.80$ & .997 & .001 & 28.80 \\
\hline
\end{tabular}






(a)

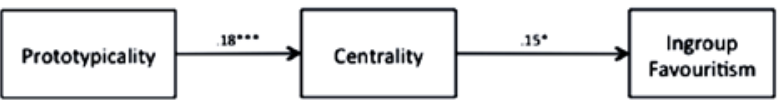

(b)

Figure 1.

In-group favoritism. (a) Initial model; (b) Final model.

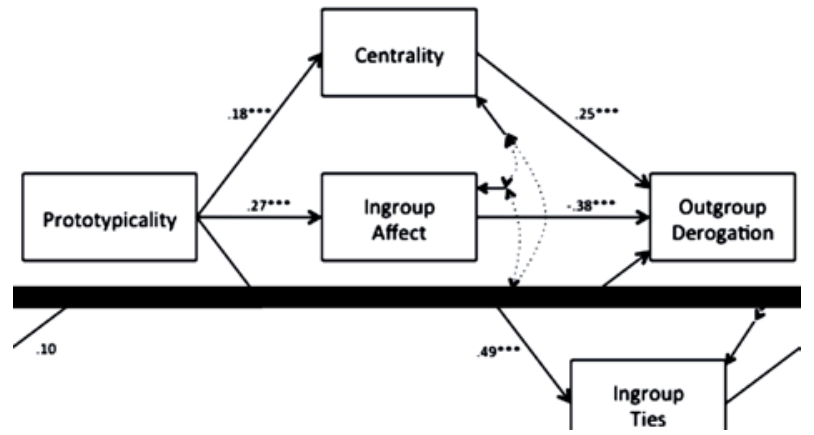

(a)

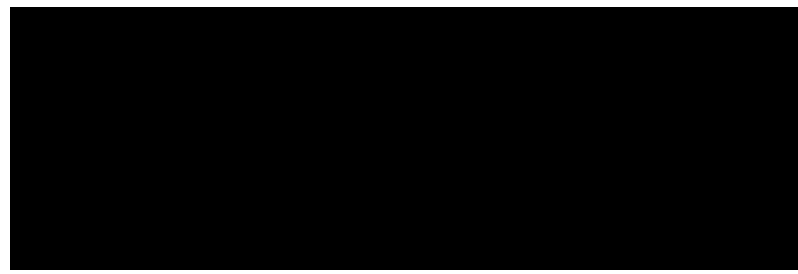

(b)

Figure 2.

Out-group derogation. (a) Initial model; (b) Final model.

that the greater a person's awareness of their group membership, the greater the likelihood of their displaying out-group hostility. However, the pathway from the affective dimension (in-group affect) was negatively related to out-group derogation. This finding suggests different processes are operating on this dimension. Those people who do not feel good about their own group membership are more motivated to engage in out-group hostility than those who evaluate their in-group identity positively or perhaps feeling good and positive about the in-group membership means that group members do not need to engage in out-group derogation.

Interestingly, while in-group affect was shown to be negatively correlated with out-group derogation, it was positively



(a)



(b)

Figure 3.

Collective self-esteem. (a) Initial model; (b) Final model.

related to collective self-esteem, indicating, as would be expected, that the better you feel about your group membership the higher your collective self-esteem. It should be noted, however, that Cameron (2004) defined in-group affect in terms highly similar to Luhtanen and Crocker's (1991) private collective self-esteem subscale; hence the high intercorrrelation between these scales is to be expected. Particularly in light of the fact that the present operationalization of collective self-esteem included state-specific items and, hence, represents a subjective evaluation of group membership.

Centrality was not significantly related to collective self-esteem suggesting that, while a stronger awareness of group membership may promote intergroup processes such as out-group derogation and in-group favoritism, it does not necessarily promote higher collective self-esteem. Rather, it is the affective aspects of social identity that positively impact on group members' collective self-esteem.

The cognitive centrality dimension was a significant predicttor of both in-group favoritism and out-group derogation, indicating that awareness and recognition of the importance of a particular social identity is an important aspect of identification in predicting inter-group outcomes. Of the many multi dimensional approaches to social identification, Cameron's (2004) measure is one of the few to assess centrality through measures of salience and importance. Most other measures include centrality as part of a more general "cognitive" or "self-categorization" component that does not distinguish it from simple inclusion. Leach et al. (2008) argue that by viewing centrality in this way, the relationship between centrality and inter-groupoutcomes is likely to be stronger. For example, they suggest that the centrality component of in-group identification will lead individuals to perceive greater threat to their in-group and, thus, encourage more active coping to defend this identity against threat. The results of the current study indicate a lack of 
association between centrality and the more internal process of collective self-esteem; a strong association between centrality and intergroup outcomes such as in-group favoritism and outgroup derogation add credence to this argument. Given that the results of the current study show the emergence of differential relationships between the dimensions of social identification and the intergroup outcome behaviors of in-group favoritism, out-group derogation, and collective self-esteem, this study provides support for the utility of examining social identification using a multidimensional model and measure.

The current study contributes significantly to the literature regarding the influence of social identification on intergroup behavior through the systematic investigation of the meditational role of the key dimensions of social identity on the relationship between prototypicality and a number of important intergroup outcome measures. Results showed clear support for the existence of a differential relationship between the dimensions of social identity and different intergroup outcomes. The salience and importance of the group identity as measured by the centrality dimension of Cameron's (2004) scale was related to both in-group favoritism and out-group derogation. Hence, awareness of group membership appears to be enough to instigate these types of intergroup processes. However, centrality did not impact incrementally on levels of collective self-esteem; it was the more affective dimensions of in-group affect and in-group ties that were related to this more internal process. The finding that in-group affect was related negatively to in-group derogation suggests that more complex processes may be occurring. Feeling good and positive about in-group membership meant that in-group members did not feel the need to engage in out-group derogation. It should be noted that the groups in the current study were chosen to be as similar to each other as possible so as to minimize any status differentials. It would be interesting to see if this finding would also emerge with out-group derogation of a higher status group.

Given that this study is the first of its kind to investigate systematically the differential effects of the dimensions of social identification on intergroup outcome behaviours, future research should examine the influence of other variables known to be important to intergroup relations - status and group size at the dimensional level of social identification. This information would assist in providing evidence to build the theoretical understanding of how the dimensions of social identification impact on specific intergroup process and help social researchers to better understand and reduce stereotyping and other negative group-related behaviours. Further, as the current study is correlational in nature, future research is needed to provide more evidence for the reliability of the current results. Overall, the results of the current study, focusing on relations between naturally occurring groups, have shown evidence for the utility of examining social identification using a multidimensional approach. Future research will benefit from adopting a multidimensional approach to gain a richer and deeper understanding of the complexities of intergroup relations and the important role that social identification plays in these intergroup processes.

\section{References}

Ashforth, B. E., \& Mael, F. (1989). Social identity theory and the or- ganisation. Academy of Management Review, 14, 20-39.

Ashmore, R., Deaux, K., \& McLaughlin-Volpe, T. (2004). An organizing framework for collective identity: Articulation and significance of multidimensionality. Psychological Bulletin, 130, 80-114. doi:10.1037/0033-2909.130.1.80

Bilewicz, M., \& Wójcik, A. (2010). Does identification predict community involvement? Exploring consequences of social identification among the Jewish minority in Poland. Journal of Community and Applied Social Psychology, 20, 72-79. doi:10.1177/0095798400026002006

Boatswain, S. J., \& Lalonde, R. N. (2000). Social identity and preferred ethnic/racial labels for Blacks in Canada. Journal of Black Psychology, 26, 216-234. doi:10.1177/0095798400026002006

Branscombe, N. R., \& Wann, D. L. (1994). Collective self-esteem consequences of out-group derogation when a valued social identity is on trial. European Journal of Social Psychology, 24, 641-657. doi:10.1002/ejsp.2420240603

Brewer, M. B. (1979). In-group bias in the minimal intergroup situation: A cognitive-motivational analysis. Psychological Bulletin, 86, 307324. doi:10.1037/0033-2909.86.2.307

Brown, R. (2000). Social Identity Theory: Past achievements, current problems and future challenges. European Journal of Social Psychology, 30, 745-778.

doi:10.1002/1099-0992(200011/12)30:6<745::AID-EJSP24>3.0.CO; $\underline{2-\mathrm{O}}$

Brown, R., Condor, S., Mathews, A., Wade, G., \& Williams, J. (1986). Explaining intergroup differentiation in an industrial organisation. Journal of Occupational Psychology, 59, 279-304. doi:10.1111/j.2044-8325.1986.tb00230.x

Cameron, J. E. (1999). Social identity and the pursuit of possible selves: Implications for the psychological well-being of university students. Group Dynamics: Theory, Research, and Practice, 3, 179-189. doi:10.1037/1089-2699.3.3.179

Cameron, J. E. (2004). A three factor model of social identity. Self and Identity, 3, 239-262. doi:10.1080/13576500444000047

Cameron, J. E., \& Lalonde, R. N. (2001). Social identification and gender-related ideology. British Journal of Social Psychology, 40, 59-77. doi:10.1348/014466601164696

Castano, E., Paladino, M., Coull, A., \& Yzerbyt, V. (2002). Protecting the in-group stereotype: In-group identification and the management of deviant in-group members. British Journal of Social Psychology, 41, 365-385. doi:10.1348/014466602760344269

Corenblum, B., \& Stephen, W. (2001). White fears and native apprehensions: An integrated threat theory approach to intergroup attitudes. Canadian Journal of Behavioural Science, 33, 251-268. doi:10.1037/h0087147

Crocker, J., \& Luhtanen, R. (1990). Collective self-esteem and in-group bias. Journal of Personality and Social Psychology, 58, 60-67. doi:10.1037/0022-3514.58.1.60

Deaux, K. (1996). Social Identification. In E. Higgins \& A. Kruglanski (Eds.), Social Psychology: Handbook of basic principles (pp. 777-798). New York: Guilford.

Diehl, M. (1990). The minimal group paradigm: Theoretical explanations and empirical findings. In W. Stroebe \& M. Hewstone (Eds.), European review of social psychology (pp. 263-292). Chichester, England: Wiley.

Doosje, B., Ellemers, N., \& Spears, R. (1995). Perceived intragroup variability as a function of group status and identification. Journal of Experimental and Social Psychology, 31, 410-436. doi:10.1037/0022-3514.58.1.60

Ellemers, N., Kortekaas, P., \& Ouwerkerk, J. W. (1999). Self-categorisation, commitment to the group, and group self-esteem as related but distinct aspects of social identity. European Journal of Social Psychology, 29, 371-389. doi:10.1002/(SICI)1099-0992(199903/05)29:2/3<371::AID-EJSP932 $>3.0 . \mathrm{CO} ; 2-\mathrm{U}$

Giguere, B. \& Lalande, R. (2010). Why do students strike? Direct and indirect determinants of collective action participation. Political Psychology, 31, 227-247. doi:10.1111/j.1467-9221.2009.00750.x 
Gurin, P., \& Markus, H. (1989). Cognitive consequences of gender identity. In S. Skevington \& D. Baker (Eds.), The Social Identity of Women (pp. 152-172). London: Sage.

Harris, G. E., \& Cameron, J. E. (2005). Multiple dimensions of organisational identification and commitment as predictors of turnover intentions and psychological well-being. Canadian Journal of Behavioural Science, 37, 159-169. doi:10.1037/h0087253

Harris, G., Cameron, J., \& Lang, J. (2011), Identification with community-based HIV agencies as a correlate of turnover intentions and general self-efficacy. Journal of Community and Applied Social Psychology, 21, 41-54

Hinkle, S., Taylor, L. A., Fox-Cardamone, D. L., \& Crook, K. F. (1989). Intragroup identification and intergroup differentiation: A multicomponent approach. British Journal of Social Psychology, 28, 305-317. doi:10.1111/j.2044-8309.1989.tb00874.x

Hogg, M. A., Abrams, D., Otten, S., \& Hinkle, S. (2004). The social identity perspective: Intergroup relations, self-conception, and small groups. Small Group Research, 35, 246-276. doi:10.1177/1046496404263424

Hogg, M. A., \& Williams, K. D. (2000). From 'I' to 'we': Social identity and the collective self. Group Dynamics: Theory, Research, and Practice, 4, 81-97. doi:10.1037/1089-2699.4.1.81

Jackson, J. W. (2002). Intergroup attitudes as a function of different dimensions of group identification and perceived intergroup conflict. Self and Identity, 1, 11-33. doi:10.1080/152988602317232777

Jetten, J., Spears, R., \& Manstead, A. (1997). Distinctiveness threat and prototypicality: Combined effects on intergroup discrimination and collective self-esteem. European Journal of Social Psychology, 27, 635-657. doi:10.1002/(SICI)1099-0992(199711/12)27:6<635::AID-E JSP835>3.0.CO;2-\#

Karasawa, M. (1991). Towards an assessment of social identity: The structure of group identification and its effects on in-group evaluations. British Journal of Social Psychology, 30, 293 - 307.

Leach, C., van Zomeren, M., Zebel, S., Vliek, M., Pennekamp, S., Doosje, B., Ouwerkerk, J., Spears, R. (2008). Self-definition and self-investment: A multi component model of in-group identification. Journal of Personality and Social Psychology, 95, 144-165. doi:10.1037/0022-3514.95.1.144

Lindeman, M. (1997). In-group bias, self-enhancement, and group identification. European Journal of Social Psychology, 27, 337-355. doi:10.1002/(SICI)1099-0992(199705)27:3<337::AID-EJSP825>3.0. $\underline{\mathrm{CO} ; 2-\mathrm{S}}$

Luhtanen, R., \& Crocker, J. (1992). A Collective Self-Esteem Scale: Self-evaluation of one's social identity. Personality and Social Psychology Bulletin, 18, 302-318. doi:10.1177/0146167292183006

Maslow, A. H. (1968). Toward a psychology of being. New York: Van Nostrand.

Obst, P. L., Smith, S. G., \& Zinkiewicz, L. (2002). An exploration of sense of community, Part 3: Dimensions and predictors of psycho- logical sense of community in geographical communities. Journal of Community Psychology, 30, 119-133. doi:10.1002/jcop.1054

Obst, P. L., \& White, K. M. (2005). Three-dimensional strength of identification across group memberships: A confirmatory factor analysis. Self and Identity, 4, 69-80. doi:10.1080/13576500444000182

Obst, P. L., Zinkiewicz, L., \& Smith, S. G. (2002). Sense of community in science fiction fandom, Part 2: Comparing neighbourhood and interest group sense of community. Journal of Community Psychology, 30, 105-117. doi:10.1002/jcop.1053

Schmitt, M. T., \& Branscombe, N. R. (2001). The good, the bad and the manly: Threats to one's prototypicality and evaluations of fellow in-group members. Journal of Experimental Social Psychology, 37, 510-517. doi:10.1006/jesp.2001.1476

Smith, E., Murphy, J., \& Coates, S. (1999). Attachment to groups: Theory and measurement. Journal of Personality and Social Psychology, 77, 94-110. doi:10.1037/0022-3514.77.1.94

Stephan, W. G., \& Stephan, C. W. (1993). Cognition and affect in stereotyping: Parallel interactive networks. In D. M. Mackie \& D. L. Hamilton (Eds.), Affect, cognition, and stereotyping: Interactive processes in-group perception (pp. 111-136). Orlando, FL: Academic Press.

Stryker, S. (1987). Identity theory: Developments and extensions. In K. Yardley \& T. Honess (Eds.), Self and identity: Psychosocial perspectives (pp. 89-103). New York: Wiley

Tajfel, H. (1978). Differentiation between social groups: Studies in the social psychology of intergroup relations. London: Academic Press.

Tajfel, H., \& Turner, J. (1979). An integrative theory of intergroup conflict. In W. Austin \& S. Worchel (Eds.), The social psychology of intergroup relations (pp. 33-47). Monterey, CA: Brooks/Cole.

Tajfel, H., Billig, M. G., Bundy, R. P., \& Flament, C. (1971). Social categorisation and intergroup behaviour. European Journal of Social Psychology, 1, 149-178. doi:10.1002/ejsp.2420010202

Turner, J. C., Hogg, M. A., Oakes, P. J., Reicher, S. D., \& Wetherell, M. S. (1987). Rediscovering the Social Group: A self-categorisation theory. Oxford: Basil Blackwell.

Verkuyten, M., \& Nekuee, S. (1999). In-group bias: The effect of selfstereotyping, identification and group threat. European Journal of Social Psychology, 29, 411-418. doi:10.1002/(SICI)1099-0992(199903/05)29:2/3<411::AID-EJSP952 $>3.0 . \mathrm{CO} ; 2-8$

Vivien, J., Hewstone, M., \& Brown, R. (1995). Changing attitudes through intergroup contact: The effects of group membership Salience. Journal of Social Psychology, 45, 342-364.

Wann, D. L., \& Grieve, F. G. (2005). Biased evaluations of in-group and out-group spectator behaviour at sporting events: The importance of team identification and threats to social identity. Journal of Social Psychology, 145, 531-546. doi:10.3200/SOCP.145.5.531-546 